\title{
PANCASILA SEBAGAI LANDASAN HUKUM DI INDONESIA
}

Oleh:

\author{
Wawan Fransisco, S.H., M.H.
}

Email: wawanfransisco@gmail.com

\begin{abstract}
Pancasila is a spiritual principle that includes an atmosphere of kebatinan or legal ideals, so it is a source of value. Norms and rules, both moral and state, and master the basic laws of both written or non-written or Convention. Pancasila is the foundation of the Republic of Indonesia as found in the Preamble of the 1945 Constitution of the Republic of Indonesia, whose birth was forged in the Indonesian national process. Pancasila historically has a legal basis in which Pancasila is the basis or direction in the making of law in Indonesia. Juridically, Pancasila is clearly the law of all sources of law in Indonesia.
\end{abstract}

Keywords : Pancasila, Staatfundamentalnorm

\section{A. PENDAHULUAN}

Pancasila merupakan dasar

Negara Indonesia yang tercantum dalam pembukaan Undang-Undang

Dasar Negara Republik Indonesia Tahun 1945. Sebagai dasar Negara, Pancasila juga sebagai sumber dari segala sumber hukum di Indonesia. ${ }^{1}$ Posisi Pancasila dalam hal ini menjadikan pedoman dan arah bagi setiap bangsa Indonesia dalam menyusun dan memperbaiki kondisi

*Wawan Fransisco, S.H., M.H., merupakan Dosen STIE STMIK-MURA Lubuklinggau Musi Rawas.

${ }^{1} \mathrm{Hal}$ ini berarti, bahwa Pancasila diletakkan pada posisi tertinggi dalam hukum di Indonesia hukum di Indonesia. Mengingat, bahwa hukum terus berubah dan mengikuti perkembangan masyarakat, maka setiap perubahan yang terjadi akan selalu disesuaikan dengan citacita bangsa Indonesia yang mengacu pada Pancasila.

Dalam rangka menuju masyarakat adil dan makmur yang menjadi tujuan bangsa dan negara Indonesia, Pancasila menjadi landasannya. Oleh sebab itu, perlu adanya tatanan dan tertib hukum dalam mengatur masyarakat dan Negara untuk mencapai tujuan tersebut. Arah dan 
acuan tersebut tentunya harus berpijak pada Pancasila. Namun demikian, dalam perjalanan Pancasila sebagai falsafah dan ideologi Negara sekaligus sebagai sumber dari segala sumber hukum di Indonesia, tentunya banyak mengalami pasang surut. Hal ini disebabkan, bahwa di era globalisasi saat sekarang ini banyaknya permasalahan baru yang muncul di tanah air, khususnya masalah korupsi, nepotisme, dan masuknya budaya dari luar yang berdampak pada perubahan budaya dalam masyarakat. Perubahanperubahan tersebut akan berdampak pada kehidupan baru masyarakat yang tentu saja membawa konsekuensi baru dari segi hukum di Indonesia.

Dalam konteks di atas, maka hukum di Indonesia juga terus mengalami perubahan untuk disesuaikan dengan permasalahan yang ada. Pancasila sebagai landasan hukum dan sumber dari segala sumber hukum di Indonesia tentunya nilai-nilai Pancasila harus terus hidup di dalam masyarakat.

Berdasarkan uraian tersebut di atas, maka dapat dirumuskan pokok permasalahan, sebagai berikut:

1. Bagaimanakah esensi Pancasila?

2. Apakah Pancasila masih menjadi acuan dalam proses membuatan undang-undang dewasa ini?

\section{B. PEMBAHASAN}

\section{Esensi Pancasila}

Pancasila dalam kedudukanya ini sering disebut sebagai dasar dasar falsafah negara (Philosofische Gronslag) dari negara, ideologi negara atau (Staatsidee). Dalam pengertian ini, Pancasila merupakan suatu dasar nilai, serta norma untuk mengatur pemerintahan negara.

Pancasila merupakan suatu dasar untuk mengatur penyelenggaraan negara. Konsekuensinya, seluruh 
pelaksanaan dan penyelenggaraan

negara terutama segala peraturan perundang-undangan termasuk proses reformasi dalam segala bidang dewasa ini dijabarkan dan diderivasikan dari nilai-nilai Pancasila.

Pancasila merupakan sumber kaidah hukum negara yang secara konstitusional mengatur negara Republik Indonesia beserta seluruh unsur-unsurnya, yaitu rakyat, wilayah, serta pemerintahan negara. $^{2}$

Hakikat Pancasila sebagai dasar nilai pengembangan ilmu pengetahuan dikemukakan

Wahyudi Sediawan dalam Simposium dan sarasehan Pancasila sebagai Paradigma Ilmu Pengetahuan dan Pembangunan Bangsa, sebagai berikut:

${ }^{2}$ Kaelan, Pendidikan Pancasila, Paradigma, Yogyakarta, 2010, hlm. 110.
Sila pertama, Ketuhanan Yang

Maha Esa memberikan kesadaran, bahwa manusia hidup di dunia ibarat sedang menempuh ujian dan hasil ujian akan menentukan kehidupannya yang abadi diakhirat nanti. Salah satu ujiannya adalah manusia diperintahkan melakukan perbuatan untuk kebaikan, bukan untuk membuat kerusakan di bumi. Tuntunan sikap pada kode etik ilmiah dan keinsinyuran, seperti: menjunjung tinggi keselamatan, kesehatan, dan kesejahteraan masyarakat, berperilaku terhormat, bertanggung jawab, etis dan taat aturan untuk meningkatkan kehormatan, reputasi dan kemanfaatan profesional, dan lain-lain adalah suatu manifestasi perbuatan untuk kebaikan tersebut. Ilmuwan yang mengamalkan kompetensi teknik 
yang dimiliki dengan baik sesuai

dengan tuntunan sikap tersebut

berarti menyukuri anugerah

Tuhan. Sila kedua, Kemanusiaan

yang Adil dan Beradab

memberikan arahan, baik bersifat

universal maupun khas terhadap

ilmuwan dan ahli teknik di

Indonesia. Asas kemanusiaan atau

humanisme menghendaki agar

perlakuan terhadap manusia harus

sesuai dengan kodratnya sebagai

manusia, yaitu memiliki

keinginan, seperti kecukupan

materi,

bersosialisasi,

eksistensinya

dihargai,

mengeluarkan pendapat, berperan

nyata dalam lingkungannya,

bekerja sesuai kemampuannya

yang tertinggi. Hakikat kodrat

manusia yang bersifat mono-

pluralis, terdiri atas jiwa dan raga

(susunan kodrat), makhluk

individu dan sosial (sifat kodrat),

dan makhluk Tuhan dan otonom (kedudukan kodrat) memerlukan

keseimbangan agar dapat

menyempurnakan kualitas

kemanusiaannya. Sila ketiga,

Persatuan Indonesia memberikan

landasan esensial bagi

kelangsungan Negara Kesatauan

Republik Indonesia (NKRI).

Untuk itu, ilmuwan dan ahli

teknik Indonesia perlu

menjunjung tinggi asas Persatuan

Indonesia ini dalam tugas-tugas

profesionalnya. Kerja sama yang

sinergis antar individu dengan

kelebihan dan kekurangannya

masing-masing akan

menghasilkan produktivitas yang

lebih tinggi dari pada

penjumlahan produktivitas

individunya. Suatu pekerjaan atau

tugas yang dikerjakan bersama

dengan semangat nasionalisme

yang tinggi dapat menghasilkan

produktivitas yang lebih optimal.

Sila keempat, Kerakyatan yang 


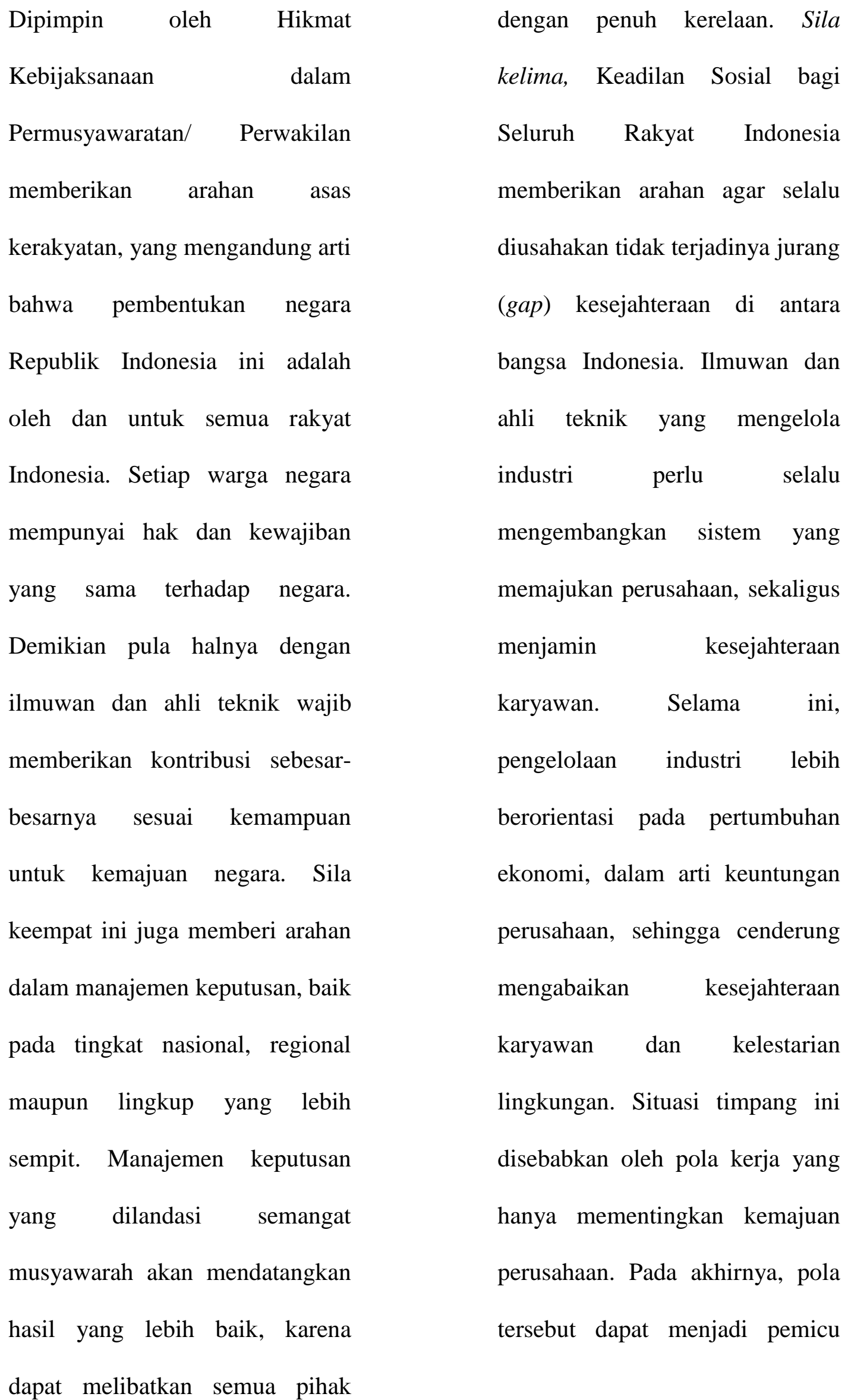


aksi protes yang justru merugikan pihak perusahaan itu sendiri. $^{3}$

Soekarno dalam rangkaian kuliah umum Pancasila Dasar Falsafah Negara pada tanggal 26 Juni 1958 sampai dengan tanggal 1 Februari 1959 sebagaimana disitir Sofian Effendi dalam Simposium dan Sarasehan Pancasila sebagai Paradigma Ilmu Pengetahuan dan Pembangunan Bangsa tanggal 14 sampai dengan 15 Agustus 2006, menyinggung perlunya setiap sila Pancasila dijadikan blueprint bagi setiap pemikiran dan tindakan bangsa Indonesia, karena kalau tidak akan terjadi kemunduran dalam pencapaian keadilan sosial bagi seluruh rakyat Indonesia. ${ }^{4}$ Pancasila sebagai blueprint dalam pernyataan Soekarno kurang lebih mengandung pengertian yang

${ }^{3}$ Direktorat Jenderal Pembelajaran dan Kemahasiswaan, Pendidikan Pancasila untuk Perguruan Tinggi, RISTEKDIKTI, Cetakan I, 2016, hlm. 216-217.

${ }^{4}$ Ibid., hlm. xiii. sama dengan Pancasila sebagai dasar nilai pengembangan iptek karena sila-sila Pancasila sebagai cetak biru harus masuk ke dalam seluruh rencana pemikiran dan tindakan bangsa Indonesia.

Konsep Pancasila sebagai dasar nilai pengembangan ilmu pernah dikemukakan oleh Notonagoro, sebagaimana dikutip oleh Koesnadi Hardjasoemantri yang menyatakan, bahwa Pancasila merupakan pegangan dan pedoman dalam usaha ilmu pengetahuan untuk dipergunakan sebagai asas dan pendirian hidup, sebagai suatu pangkal sudut pandangan dari subjek ilmu pengetahuan dan juga menjadi objek ilmu pengetahuan atau hal yang diselidiki. ${ }^{5}$ Penggunaan istilah "asas dan pendirian hidup" mengacu pada sikap dan pedoman yang menjadi rambu normatif ${ }^{5}$ Ibid., hlm. xii. 
dalam tidakan dan pengambilan keputusan ilmiah. ${ }^{6}$

Dengan

ditetapkannya

Pancasila

sebagai

Staatsfundamentalnorm, maka

pembentukan hukum, penerapan,

dan pelaksanaannya tidak dapat

dilepaskan dari nilai nilai

Pancasila. Namun, dengan

penempatan Pancasila sebagai

Staatsfundamentalnorm berarti

menempatkannya di atas Undang-

Undang Dasar. Jika demikian,

Pancasila tidak termasuk dalam

pengertian konstitusi, karena

berada di atas konstitusi. Dengan

melacak pada norma dasar dan

konstitusi menurut Kelsen dan

pengembangan yang dibuat Hans

Nawiasky, serta melihat hubungan

antara Pancasila dan Undang-

Undang Dasar 1945, memang

hingga kini masih terjadi polemik

di kalangan ahli Proklamasi
Kemerdekaan, sebenarnya yang

dapat disebut sebagai sumber dari

segala sumber hukum.

Polemik ini mencuat ketika

Moh.Yamin pada tahun 1959

menggunakan istilah sumber dari

segala sumber hukum tidak untuk

Pancasila, seperti yang lazim

digunakan saat ini, melainkan

untuk Proklamasi Kemerdekaan

17 Agistus 1945 yang disebut

dengan "maha-sumber dari segala

sumber hukum, the source of the

source" ${ }^{7}$

\section{Sumber Yuridis Pancasila} sebagai Dasar Negara

Secara yuridis ketatanegaraan,

Pancasila merupakan dasar negara

Republik Indonesia sebagaimana

terdapat pada Pembukaan

Undang-Undang Dasar Negara

Republik Indonesia tahun 1945, yang kelahirannya ditempa dalam

proses kebangsaan Indonesia. 
Melalui Undang-Undang Dasar

Negara Republik Indonesia tahun

1945 sebagai payung hukum,

Pancasila perlu diaktualisasikan

agar dalam praktik

berdemokrasinya tidak kehilangan

arah dan dapat meredam konflik

yang tidak produktif. ${ }^{8}$ Peneguhan

Pancasila sebagai dasar negara

sebagaimana terdapat pada

pembukaan, juga dimuat dalam

Ketetapan MPR Nomor

XVIII/MPR/1998, tentang

Pencabutan Ketetapan MPR

Nomor II/MPR/1978 tentang

Pedoman Penghayatan dan

Pengamalan Pancasila

(Ekaprasetya Pancakarsa) dan

ketetapan tentang Penegasan

Pancasila sebagai Dasar Negara.

Meskipun status ketetapan MPR

tersebut saat ini sudah masuk

dalam kategori ketetapan MPR

yang tidak perlu dilakukan
${ }^{8}$ Pimpinan MPR dan Tim Kerja Sosialisasi MPR Periode 2009-2014, 2013, hlm. 89. tindakan hukum lebih lanjut, baik

karena bersifat einmalig (final),

telah dicabut maupun telah selesai

dilaksanakan. ${ }^{9}$ Selain itu, juga

ditegaskan dalam Undang-

Undang Nomor 12 tahun 2011

tentang Pembentukan Perundang-

undangan bahwa Pancasila

merupakan sumber dari segala

sumber hukum negara.

Penempatan Pancasila sebagai

sumber dari segala sumber hukum

negara, yaitu sesuai dengan

Pembukaan Undang-Undang

Dasar Negara Republik Indonesia

tahun 1945, bahwa Pancasila

ditempatkan sebagai dasar dan

ideologi negara serta sekaligus

dasar filosofis bangsa dan negara

sehingga setiap materi muatan

peraturan perundang-undangan

tidak boleh bertentangan dengan
${ }^{9}$ Pimpinan MPR dan Tim Kerja Sosialisasi MPR periode 2009-2014, 2013, hlm. 90. 
nilai-nilai yang terkandung dalam

Pancasila. $^{10}$

Dalam proses reformasi dewasa ini MPR melalui sidang istimewa tahun 1998, mengembalikan kedudukan pancasila sebagai dasr negara republik indonesia yang tertuang dalam Tap. No. XVIII/MPR/1998. Oleh karena itu segala agenda dalam proses reformasi, yang meliputi berbagai bidang selain mendasarkan pada kenyataan aspirasi rakyat (Sila IV) juga harus mendasarkan pada nilainilai yang terkandung dalam pancasila.reformasi tidak mungkin menyimpang dari nilai ketuhanan, kemanusiaan, persatuan, kerakyatan serta keadilan, bahkan harus bersumber kepadanya. $^{11}$

Berkaitan dengan masalah diatas tentunya bahwa Pancasila

\footnotetext{
${ }^{10}$ Ibid, hlm. 85

${ }^{11}$ Kaelan, Op. Cit., hlm. 112
}

secara historis memiliki suatu dasar hukum dimana Pancasila sebagai ladasan atau arah dalam pembuatan hukum di Indonesia. Secara yuridis Pancasila sudah jelas menjadi hukum dari segala sumber hukum di Indonesia. Meskipun Pancasila dalam perjalannanya juga mengalami pasang surut, tetapi Pancasila sampai saat sekarang masih menjadi landasan dalam setiap pembuatan peraturan. Hal ini didalam setiap undang undang selalu mencantumkan nilai- nilai Pancasila.

\section{PENUTUP}

Pembangunan hukum dimulai dari pondasi dan jiwa paradigma bangsa Indonesia. Pancasila sebagai sumber dari segala sumber hukum yang tertegas dalam Undang-Undang Nomor 12 Tahun 2011 Tentang Pembentukan Peraturan Perundang Undangan, yang menyatakan 
Pancasila merupakan sumber dari segala sumber hukum atau tertib hukum bagi kehidupan hukum Indonesia, kama hal tersebut dapat diartikan, bahwa "Penempatan Pancasila sebagai sumber dari segala sumber hukum Negara adalah sesuai dengan pembukaan Undang-Undang Dasar Negara Republik Indonesia Tahun 1945 yang menempatkan Pancasila sebagai dasar dan idiologi Negara serta sekaligus dasar filosofi bangsa dan Negara sehingga tiap materi muatan peraturan perundang undangan tidak boleh bertentangan dengan nilai-nilai Pancasila. Kedudukan Pancasila sebagai sumber hukum Negara merupakan Groundnorm dalam sistem hukum Indonesia yang memberikan arah dan jiwa serta menjadi paradigma normanorma dalam pasal-pasal UndangUndang Dasar Negara Republik Indonesia Tahun 1945. Cita hukum dan falsafah hidup serta moralitas bangsa yang menjadi sumber segala sumber hukum Negara akan menjadi satu fungsi krisisi dalam menilai kebijaksanaan hukum (Legal Policy) atau dapat dipergunakan sebagai pardigma yang menjadi landasan perbuatan kebijaksanaan (Policy Making) dibidang hukum dan perundang undangan maupun bidang social, ekonomi, dan politik.

\section{DAFTAR PUSTAKA}

Direktorat Jenderal Pembelajaran dan Kemahasiswaan. 2016. Pendidikan Pancasila untuk Perguruan Tinggi. RISTEKDIKTI. Cetakan I. Jakarta.

Kaelan. 2010. Pendidikan Pancasila. Paradigma, Yogyakarta.

Kurnisar. "Pancasila Sumber dari Segala Sumber Hukum di Indonesia". $e$ journal. Undiksha.ac.id.

Republik Indonesia. Undang-Undang Dasar Negara Republik Indonesia Tahun 1945.

Republik Indonesia. Undang-Undang Nomor 12 Tahun 2011 Tentang Pembentukan Peraturan Perundang-undangan (Lembaran Negara Republik Indonesia Tahun 2011 Nomor 82, Tambahan Lembaran Negara Republik Indonesia Nomor 5234). 